\title{
Dynamic Response Analysis of a Bulk Carrier by Nonlinear Hydroelastic Method
}

\author{
Zhanyang Chen ${ }^{1,2, *\left(\mathbb{D}, \text { Hongbin Gui }^{1}, \mathrm{Xiyu}_{\text {Liao }}{ }^{1} \text { and Mengchao Du }\right.}{ }^{1}$ \\ 1 Department of Ocean Engineering, Harbin Institute of Technology at Weihai, Weihai 264209, China; \\ guihongbin@sina.com (H.G.); zhalanlxy@163.com (X.L.); 17863109150@163.com (M.D.) \\ 2 State Key Laboratory of Coastal and Offshore Engineering, Dalian University of Technology, \\ Dalian 116024, China \\ * Correspondence: chenzhanyang@hit.edu.cn; Tel.: +86-1350-6318-766
}

Citation: Chen, Z.; Gui, H.; Liao, X.; $\mathrm{Du}, \mathrm{M}$. Dynamic Response Analysis of a Bulk Carrier by Nonlinear Hydroelastic Method. J. Mar. Sci. Eng. 2021, 9, 877. https://doi.org/ 10.3390/jmse9080877

Academic Editor: Md Jahir Rizvi

Received: 17 July 2021

Accepted: 10 August 2021

Published: 13 August 2021

Publisher's Note: MDPI stays neutral with regard to jurisdictional claims in published maps and institutional affiliations.

Copyright: (c) 2021 by the authors. Licensee MDPI, Basel, Switzerland. This article is an open access article distributed under the terms and conditions of the Creative Commons Attribution (CC BY) license (https:// creativecommons.org/licenses/by/ $4.0 /)$.

\begin{abstract}
With increasing demands for huge ship dimensions and the wide use of high-strength steel, the influence of slamming and elastic structure on structural strength cannot be ignored. Therefore, in this paper, a three-dimensional (3D) nonlinear hydroelastic theory is introduced, in which the nonlinear hydrostatic restoring force caused by instantaneous wetted surface as well as slamming force are taken into consideration, and the bending moments with/without slamming effects are calculated, respectively. Numerical simulations of the dynamic response of a flexible hull at different speeds are carried out using the finite element analysis software MSC/PATRAN. By comparison with the results of classical beam theory, the accuracy of the dynamic analysis method is studied. Finally, the dynamic response method is compared with the quasi-static method and classical beam theory. By analyzing and quantifying the influence of forward speed and nonlinear factors on structural responses, the reasonable applicable conditions for different methods are discussed, which can be used as reference in the structure design of bulk carriers.
\end{abstract}

Keywords: nonlinear; hydroelasticity; dynamic response analysis; slamming; finite element method

\section{Introduction}

With the rapid development of the maritime transport industry and the speed of the construction of merchant ships, large-scale ships are becoming more and more popular. As large and complex sea transport, ship structural damage problems may cause the loss of materials and personnel casualties. Therefore, in order to eliminate hull structure damage and failure phenomena of security risks, the calculations of the structure responses of hulls must be accurate and reliable.

The load responses induced by waves have a very important impact on the structure safety assessment of hulls. The traditional hull is regarded as a rigid structure, and the wave loads of a rigid body have been extensively used in structural strength assessment [1-3]. However, the increase of ships' scale makes the coupling between the hull structure and the fluid more and more obvious, so the rigid theory has been unable to meet today's computing needs. Now wave-induced large-scale ship hydroelastic response has become an important research topic [4-6]. Furthermore, modern ships with high speed and complex structure are subject to the slamming phenomenon frequently in the extreme sea states, which, obviously, may bring about nonlinear ship motions and wave loads, which would cause a serious threat to hull structure. Lavroff et al. [7] studied the peak wave slamming loads based on a hydroelastic segmented model experiment of the $112 \mathrm{~m}$ INCAT Tasmania wave-piercer catamaran. Peak slam loads measured on the center bow were found to approach the total weight of the model. It was found that global dimensionless heave and pitch accelerations peaked in the same range of encounter frequency, so did the peak slam load. Lind et al. [8] presented a new algorithm that remedies this issue, giving stable and accurate solutions to both internal and free-surface flows. The algorithm 
was validated against analytical solutions for an internal flow at higher Reynolds numbers than previously. Lind et al. [9] proposed a two-phase incompressible-compressible smoothed particle hydrodynamics (SPH) method for water and air, respectively. Results were compared with experimental measurements, and numerical predictions of impact pressure are quite accurate. The air was shown to have a significant cushioning effect for impact on flat water and this reduces for waves as the ratio of wave height to wave length increases. Xia et al. [10] discussed the dynamic response of a SWATH under slamming load. Slamming load that varies with space and time was derived by using of the relative motion, and the dynamic response was calculated.

The ship model experiment, as an important practical method, is applied widely in the hydrodynamic field and numerical method validation. Lin et al. [11] presented an approximate method of symmetric and asymmetric flare slamming analysis based on global ship response in the time domain. For the sake of practicability, the present numerical results are further validated using the segmented model experiment results and CFD results for a 10,000 TEU container ship. Zong et al. [12] conducted a vertical water entry experiment of a 2D trimaran section from different drop heights and flow fields by using PIV technology for each condition. The lots of conclusions were obtained based on the test results. Besides, some scholars have studied the wave loads and slamming problem of trimarans by means of model experiments [13,14].

The analysis of structural responses can be roughly divided into static method and dynamic analysis method. Both methods have their advantages. In order to reflect the dynamic effect, the time-domain dynamic method is recommended for the structural response analysis. Besides, It has been confirmed that it is feasible to investigate the structural strength of hulls by the hydroelastic time domain method [15,16]. However, as for the dynamic analysis method, the computational efficiency and computer's memory will become a major restrictive factor. The results are affected by many parameters and the calculation process is not stable enough. While the static method is convenient, the calculation accuracy is often not satisfactory.

As is known, the principle of hull structure design is to ensure sufficient strength and to avoid strength redundancy, which is especially true for high-speed ships with high lightweight requirements. While many scholars have studied these two methods, there is no accurate statement about the applicability of these methods. Therefore, the main objective of this study is efficient and accurate estimation of dynamic responses of a flexible hull. For this purpose, a time-domain nonlinear hydroelastic method is developed. In the hydrodynamic part, the nonlinear hydrostatic restoring force caused by instantaneous wetted surface as well as the slamming force are considered. In the structure part, the numerical simulation of dynamic responses of a flexible hull is done by means of the finite element method (FEM). By analyzing and quantifying the influence of forward speed and nonlinear factors on structural responses, the reasonable applicable conditions for different methods are discussed.

\section{Nonlinear Hydroelastic Theory}

\subsection{Basic Formulations}

In this paper, the hull is assumed to have a flexible body and to be traveling in waves. A ship-fixed right-handed coordinate system $O-x y z$ was applied. The positive $z$ points upward and the positive $x$ is towards the bow. The $x O y$ plane is coincident with the still water level. In order to predict the ship hydroelastic responses, the fluid is assumed to be inviscid and incompressible and the flow is irrotational.

The "Source-Sink Distribution Method" was used to solve the diffraction potential and radiation potential (incident potential is known) of the flow field around the flexible hull in which the Price-Wu boundary condition was adopted for the fluid-structure interface $[17,18]$. In general, the ship motion in waves is usually viewed as a forced vibration under the action of wave excitation, so we have,

$$
[a] \ddot{p}_{r}(t)+[b] \dot{p}_{r}(t)+[c] p_{r}(t)=\{F(t)\}
$$


where the elements $[a]$ and $[c]$ can be determined through the orthogonality of the system mass matrix and the stiffness matrix of the modal function using the transfer matrix method. The structure damping matrix $[b]$ can be obtained experimentally or empirically.

$\{F(t)\}$ denotes the total fluid forces at each instant time, which can be composed of a series of fluid forces acting on the hull:

$$
\{F(t)\}=\left\{F_{S}(t)\right\}+\left\{F_{I}(t)\right\}+\left\{F_{D}(t)\right\}+\left\{F_{R}(t)\right\}+\left\{F_{\text {slamming }}(t)\right\}
$$

where $\left\{F_{s}(t)\right\}$ is the hydrostatic restoring force; $\left\{F_{I}(t)\right\}$ and $\left\{F_{D}(t)\right\}$ are the incident wave force and the diffraction wave force, respectively; $\left\{F_{R}(t)\right\}$ is the radiation force of the hull; $\left\{F_{\text {slamming }}(t)\right\}$ is the slamming force.

In the following sections, each fluid force in Equation (2) will be calculated. In order to take more factors into calculation to meet the requirement of practical engineering, some nonlinear terms, such as nonlinear restoring force and nonlinear wave exciting force caused by instantaneous wetted surface as well as slamming force are added to the motion Equation (1) artificially.

\subsection{Nonlinear Fluid Forces}

The iterative calculation is used to obtain the ship's motion and load responses at every time step when the ship moves around the mean position. Since the position of the ship relative to the wave changes all the time, the component forces are calculated on the instantaneous wetted surface meshes of the hull by the time domain method. Bow slamming and green water on the deck, which are caused by large amplitude motions, are also taken into account in the time domain simulation.

According to the Cummins theory [19], the $r$-th order component of generalized hydrodynamic forces of ships can be expressed as:

$$
Z_{r}(t)=-\iint_{S(t)} \vec{n} \cdot \vec{u}_{r} \cdot P d s(r=1,2, \cdots m)
$$

where $P$ is pressure; $\vec{n}$ is the normal vector; $\vec{u}_{r}$ is the $r$-th displacement vector of the flexible structure; $r=1,2 \ldots 6$ denotes six degrees of freedom rigid motions; $r \geq 7$ denotes the elastic mode.

The hydrostatic pressure acting on the hull is:

$$
P_{S}(t)=-\rho g z=-\rho g\left(\sum_{k=1}^{m} w_{k} p_{k a}(t)\right)
$$

where $\rho$ is the density of water; $g$ is the acceleration of gravity; $p_{k a}(t)$ is the amplitude of $k$-th principal coordinates; $w_{k}$ is the $k$-th vertical displacement, is also independent of time and can be calculated in advance.

Based on the 3D hydroelasticity theory [20], the $r$-th hydrostatic restoring force can be directly calculated through the composition method including the integration of hydrostatic pressure on instantaneous wetted surface $S(t)$ and hull gravity $F_{G}$.

$$
\begin{gathered}
F_{S}^{r}(t)=-\rho g \sum_{k=1}^{m} p_{k a} \iint_{S(t)} \vec{n} \cdot \vec{u}_{r} w_{k} d s-F_{G}^{r} \\
F_{G}^{r}=\iint_{S(t)} F_{g} \cdot w_{r} d s
\end{gathered}
$$

where $F_{g}$ is the weight collection degree of each station.

The incident wave force and diffraction force on the instantaneous wetted surface of the hull can be given as [20]:

$$
\left\{\begin{array}{l}
F_{I}(t)=-\rho \zeta_{a} \iint_{S(t)} \vec{n} \cdot \vec{u}_{r}\left(i \omega-U \frac{\partial}{\partial x}\right) \phi_{0} d s \\
F_{D}(t)=-\rho \zeta_{a} \iint_{S(t)} \vec{n} \cdot \vec{u}_{r}\left(i \omega-U \frac{\partial}{\partial x}\right) \phi_{d} d s
\end{array}\right.
$$


where $\zeta_{a}$ is wave amplitude; $\vec{u}_{r}$ is the $r$-th principal modes of the structure; $\omega$ is the wave frequency; $\phi_{0}$ and $\varphi_{d}$ are the instantaneous incident potential and diffraction potential under unit wave amplitude, respectively.

The radiation force has relations with hull nonlinear motion, which takes the form [20]:

$$
\left\{F_{R}(t)\right\}=-[A(t)]\left\{\ddot{p}_{r}(t)\right\}-[B(t)]\left\{\dot{p}_{r}(t)\right\}
$$

where the hydrodynamic coefficients (added mass and damping) corresponding to different $\omega$ are obtained by the frequency-domain hydroelastic method as follows:

$$
\left\{\begin{array}{c}
A_{r k}=\frac{-\rho}{\omega^{2}} \operatorname{Re} \iint_{S(t)} \vec{n} \cdot \vec{u}_{r}\left(i \omega-U \frac{\partial}{\partial x}\right) \varphi_{k} d s \\
B_{r k}=\frac{\rho}{\omega} \operatorname{Im} \iint_{S(t)} \bar{n} \cdot \vec{u}_{r}\left(i \omega-U \frac{\partial}{\partial x}\right) \varphi_{k} d s
\end{array}\right.
$$

where $\varphi_{k}(x, y, z, t)$ is the instantaneous radiation potential per wave amplitude.

The Wagner model and momentum impact theory are the classical methods used to solve the slamming event in the time domain simulation. In this study, the momentum impact theory is adopted to calculate the bow flare impact pressures. It is considered that the slamming force depends on the momentum change rate of the fluid around the bow. Slamming force could be obtained by using the following equation:

$$
F_{f}(x, t)=-\left\{\frac{d}{d t}\left[m(x, t) \frac{d}{d t} Z_{R}(x, t)\right]-\rho g s(x, t)\right\}
$$

where, $m(x, t)$ denotes the instantaneous added mass; $s(x, t)$ denotes the instantaneous wetted area; $Z_{R}(x, t)$ denotes the vertical ship motion relative to the incident wave.

Since the hydroelasticity theory needs to take into consideration the ship elastic deformations, the vertical relative ship velocity to the incident wave should be written as follows:

$$
\frac{d}{d t} Z_{R}(x, t)=\sum_{r=1}^{m} w_{r}(x) \dot{p}_{r}(t)-\dot{\zeta}
$$

where $\dot{\zeta}$ is the wave vertical velocity.

Then, the slamming load of each mode was integrated on an instantaneous wetted surface $S(t)$; the $r$-th slamming force considering the vibration modes can be expressed as [20]:

$$
F_{\text {slamming }}^{r}(t)=\iint_{S(t)} F_{f}(t) \cdot w_{r} d s
$$

\subsection{Hydroelastic Time-Domain Motion Equation and Modal Analysis}

With all the fluid forces acting on the hull being obtained, according to the unified theory of hydroelasticity [20], the generalized equation of motion of hulls can be written as:

$$
([a]+[A]) \ddot{p}_{r}(t)+([b]+[B]) \dot{p}_{r}(t)+([c]+[C]) p_{r}(t)=\left\{F_{I}(t)\right\}+\left\{F_{D}(t)\right\}+\left\{F_{\text {slamming }}(t)\right\}
$$

For the solution of Equation (13), the "Fourth-order Runge-Kutta" method was adopted to obtain the principal coordinates. The total time-domain displacement $w(x, t)$, bending moments $M(x, t)$ and shear forces $V(x, t)$ at each time-step and cross-section can be obtained through the modal superposition method:

$$
\left.\begin{array}{rl}
w(x, t) & =\sum_{r=1}^{m} p_{r}(t) w_{r}(x) \\
M(x, t) & =\sum_{r=1}^{m} p_{r}(t) M_{r}(x) \\
V(x, t) & =\sum_{r=1}^{m} p_{r}(t) V_{r}(x)
\end{array}\right\}
$$

where $w_{r}(x), M_{r}(x)$ and $V_{r}(x)$ are the $r$-th natural vibration modes of displacement, bending moment and shearing force of ships, respectively, which can be obtained through the transfer matrix method (TMM) or finite element method (FEM). This paper took a bulk carrier as an example, and MSC. Patran was used to perform FEM simulations. The global finite element model of a bulk carrier is shown in Figure 1. Station 0 starts from the aft 
perpendicular. The shell elements and bar elements are used to simulate the stiffener and plate structures, respectively. The total number of elements is 354,680 , including 200,842 shell elements and 153,838 bar elements. Besides, the shell elements include 20,349 triangular elements and 180,493 quadrilateral elements. Table 1 lists the main particulars of the bulk carrier.

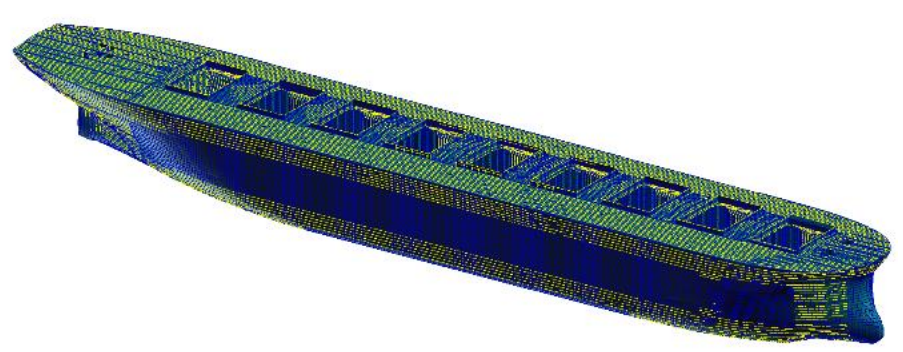

Figure 1. Finite element model of the bulk carrier.

Table 1. Main parameters of the bulk carrier.

\begin{tabular}{cc}
\hline Principal Dimension & Prototype Ship \\
\hline Length overall/m & 223.00 \\
Waterline length/m & 213.00 \\
Breadth $/ \mathrm{m}$ & 32.20 \\
Depth/m & 17.80 \\
Draft/m & 11.85 \\
Displacement/ton & $59,104.33$ \\
\hline
\end{tabular}

In actual engineering, the first three orders of elastic modes are suitable [21]. So the six orders of rigid modes and three orders of elastic modes $(r=9)$ are considered to improve the calculation efficiency. In this study the computations are made on an $8 \mathrm{CPU}$ workstation with $3.4 \mathrm{GHz}$ on the windows Win10 system. Based on the accumulative chord length cubic parameter spline theory, the hydrodynamic grids of the elastic hull are accomplished. By combining the existing wetted surface mesh generation method of the rigid hull and the $3 \mathrm{D}$ vibration model obtained by FEM, a hybrid wetted surface mesh generation method for elastic hull is presented. The wetted surface model for hydrodynamic calculation includes 1422 meshes.

\section{Analysis of Structural Dynamic Responses}

\subsection{Dynamic Analysis Theory}

The whole process of dynamic response analysis of hull structure is divided into five steps:

(1) The determination of dynamic analysis method;

(2) The establishment accurate calculation model;

(3) The application of dynamic loads and boundary conditions;

(4) The determination of solving method;

(5) Evaluation and analysis of the results.

For the determination of dynamic analysis method, the modal superposition method was applied in this paper. The undamping vibration mechanics equation can be written as:

$$
[M]\left\{\ddot{p}_{r}(t)\right\}+[K]\left\{p_{r}(t)\right\}=\{F(t)\}
$$

where $[M]$ is the mass matrix of whole structure; $[K]$ is the stiffness matrix of whole structure; $\{F(t)\}$ is the force vector.

After the principal mode and natural frequency of structure were obtained, the modal matrix was used for the orthogonal transformation [22]:

$$
\left\{p_{r}(t)\right\}=[\varphi]\{\xi(t)\}
$$

Substituting Equation (16) into the Equation (15), the modal coordinate equation may be expressed as follows. 


$$
[M][\varphi]\{\ddot{\xi}(t)\}+[K][\varphi]\{\widetilde{\zeta}(t)\}=\{F(t)\}
$$

Multiplying by $[\phi]^{T}$ on both sides of Equation (17), we have,

$$
[\varphi]^{T}[M][\varphi]\{\ddot{\xi}(t)\}+[\varphi]^{T}[K][\varphi]\{\tilde{\xi}(t)\}=[\varphi]^{T}\{F(t)\}
$$

where $[\phi]^{T}[M][\phi]$ is the modal mass matrix; $[\phi]^{T}[K][\phi]$ is the modal stiffness matrix; $[\varphi]^{T}\{p(t)\}$ is the modal force vector.

By using the orthogonal characteristic of the vibration mode, we have,

$$
\ddot{\xi}_{i}(t)+\omega_{i}^{2} \tilde{\xi}_{i}(t)=N_{i}(t)
$$

where $\xi_{i}$ is the $i$-th order displacement; $\omega_{i}$ is the $i$-th order frequency; $N_{i}$ is the $i$-th force.

For the each independent one-degree-of-freedom equation, the Duhamel integrations are performed to obtain the final result.

\subsection{Work Condition for Hydrodynamic Calculation}

Generally speaking, for structural analysis, the work condition with the maximum wave load, which is the worst condition, has attracted most attention. Thus, the most dangerous wave angle, wave frequency and wave amplitude should be determined before predicting the wave loads. In this paper the software "COMPASS-WALCS" is used for the combined condition with the several wave angles and wave frequencies. The wave angle range is from $0^{\circ}$ to $180^{\circ}$, and the wave frequency range is from $0.1 \mathrm{rad} / \mathrm{s}$ to $1.5 \mathrm{rad} / \mathrm{s}$. Besides, the wave amplitudes are determined by means of long-term forecast, where the exceedance probability of the wave is taken as $1.0 \times 10^{-8}$. Figure 2 presents the VBM variation corresponding to $15 \mathrm{kn}$ by using WALCS. Then, the most dangerous wave angle, wave frequency, cross-section and wave amplitude for hydrodynamic calculation can be determined, as shown in Table 2.

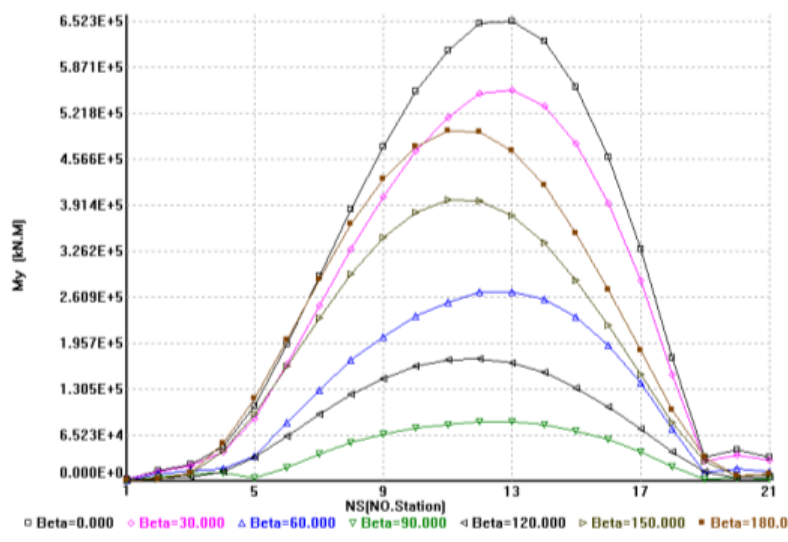

(a)

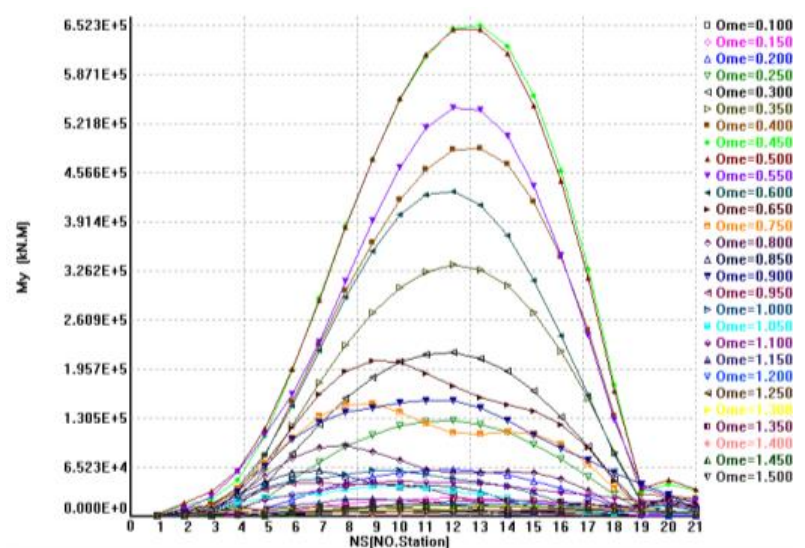

(b)

Figure 2. Variation of VBM with ship length $(v=15 \mathrm{kn})$. (a) Under different wave angles; (b) under different wave frequencies.

Table 2. Calculated work condition.

\begin{tabular}{ccccc}
\hline Speed/kn & ${\text { Wave Angles } /{ }^{\circ}}$ & Wave Frequency/rad/s & Section (Distance from Aft Perpendicular)/m & Wave Amplitude/m \\
\hline 5 & 0 & 0.5 & No. 12 (149.7) & 10.264 \\
10 & 0 & 0.5 & No. 12 (149.7) & 8.979 \\
15 & 0 & 0.45 & No. 13 (162.5) & 9.164 \\
\hline
\end{tabular}

\subsection{Loading Mode of Dynamic Analysis Method}

Application of loads in the dynamic analysis method is same as that in the quasi-static method. Firstly, the hydrostatic loads were applied according to the ship floating state. Secondly, the wave loads obtained by the 3D nonlinear hydroelastic method proposed in this paper were applied. Finally, inertia relief was applied to satisfy the boundary condition. 
It is worth noting that the wave loads in the quasi-static method are static loads that are not time varying. However, the wave loads in the dynamic analysis method belong to a kind of dynamic load varying with time. This means that the stress change of each wet grid needs to be analyzed. Table 3 presents some results of time-domain stress of wet surface.

Table 3. Stress of mesh of wet surface (Pa).

\begin{tabular}{ccccccc}
\hline Mesh Number & $\boldsymbol{t}_{\mathbf{1}}$ & $\boldsymbol{t}_{\mathbf{2}}$ & $\boldsymbol{t}_{\mathbf{3}}$ & $\boldsymbol{t}_{\mathbf{4}}$ & $\boldsymbol{t}_{\mathbf{5}}$ & $\boldsymbol{t}_{\mathbf{6}}$ \\
\hline 3600 & 276,705 & $274,841.4$ & $269,276.1$ & $260,083.5$ & $135,839.1$ & 187,677 \\
3601 & $247,387.8$ & $231,360.3$ & $212,216.1$ & $190,213.5$ & $229,437.3$ & $258,877.8$ \\
3602 & $165,649.2$ & $138,853.5$ & $110,187.3$ & $80,037.3$ & $274,417.5$ & $275,222.1$ \\
3603 & $48,809.1$ & $16,923.3$ & $-15,190.2$ & $-47,099.1$ & $261,248.4$ & $233,246.7$ \\
3603 & $-78,373.8$ & $-108,593$ & $-137,349$ & $-164,255$ & $192,720.3$ & $141,845.7$ \\
3604 & $-188,949$ & $-211,098$ & $-230,403$ & $-246,605$ & $83,354.7$ & $20,387.7$ \\
$\ldots$ & $\ldots$ & $\ldots$ & $\ldots$ & $\ldots$ & $\ldots$ & $\ldots$ \\
\hline
\end{tabular}

In order to achieve a compromise between computation efficiency and accuracy, a PCL language program is compiled for the application of wave loads in this paper. Based on the new PCL language program, the influence of the time variable is considered for the cyclic application of loads in multiple time steps. This indicates that the time-dependent wave force field is inputted into MSC. Patran directly. After the analysis and processing through Patran, it would be submitted to Nastran for relevant dynamic operations. It has been confirmed that the developed algorithms are reproducible and others can use this method to carry out calculations.

\subsection{Results of Dynamic Analysis Method}

The purpose of this section is to analyze the dynamic responses of the structure at the speeds of $5 \mathrm{kn}, 10 \mathrm{kn}$ and $15 \mathrm{kn}$. Since the wave loads in the stable period were chosen for the application of loading, the time histories of stresses and deformations show the periodic change, so the results in a single period need to be studied. In this section, four typical time steps, $0.125 T, 0.25 T, 0.75 T$ and $0.825 T$ ( $T$ denotes the period), were chosen to display the element results, which are shown in Figures 3-6, where the periods of ship deformation at these three speeds are 11.1085 s, 9.9538 s and 10.3096 s, respectively. The deformation of the hull with time at different speeds can be observed. The ship is in the hogging condition at $t=0.125 \mathrm{~T}$ and $t=0.25 \mathrm{~T}$, and the ship is in the sagging condition at $t=0.75 \mathrm{~T}$ and $t=0.875 \mathrm{~T}$. Besides, the deformations of the ship at the three speeds are very similar, and the peak value of stress increases as the forward speed increases.

The dangerous cross-section (the distance from the aft perpendicular is $149.7 \mathrm{~m}$ ) was obtained by means of the nonlinear hydroelastic method proposed in this paper. Through the MSC. Patran, the time-domain upper deck bending stresses of the dangerous crosssection were obtained and presented in Figure 7. As shown in Figure 7, with the increasing of forward speed, the high-frequency stress components increase remarkably.

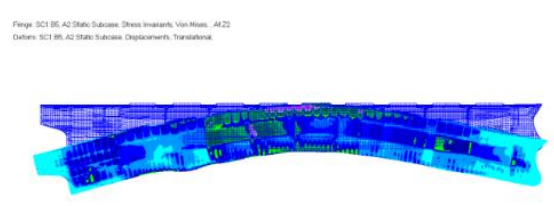

(a)

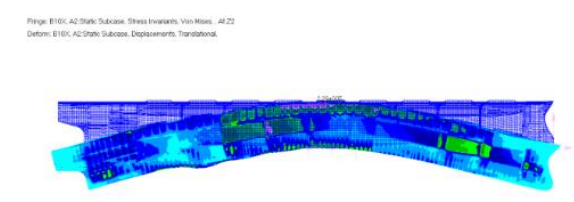

(b)

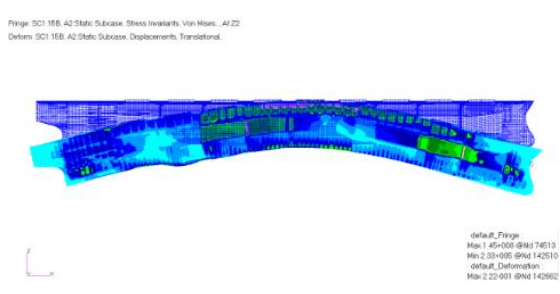

(c)

Figure 3. Ship deformation at $t=0.125 \mathrm{~T}$. (a) $5 \mathrm{kn}$; (b) $10 \mathrm{kn}$; (c) $15 \mathrm{kn}$. 


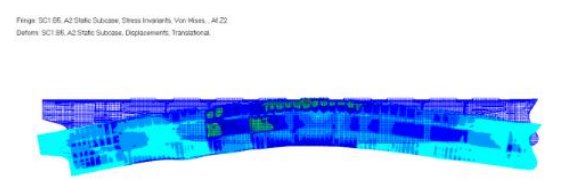

(a)
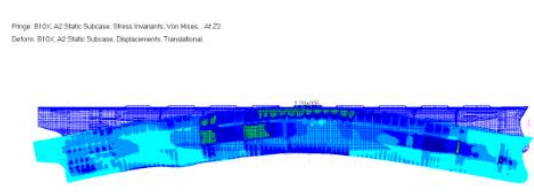

(b)

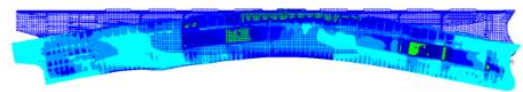

(c)

Figure 4. Ship deformation at $t=0.25 \mathrm{~T}$. (a) $5 \mathrm{kn}$; (b) $10 \mathrm{kn}$; (c) $15 \mathrm{kn}$.

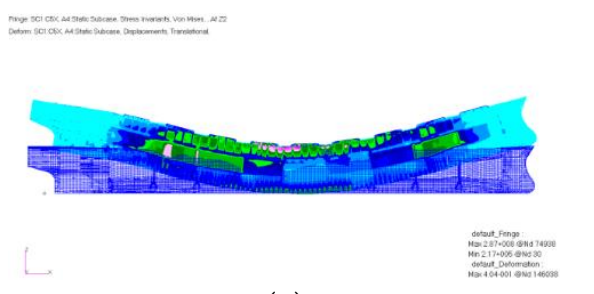

(a)

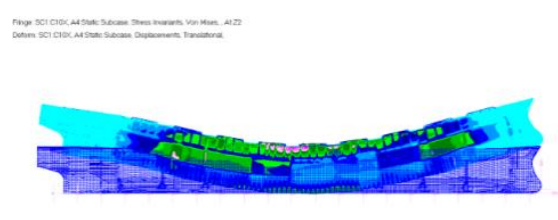

(b)

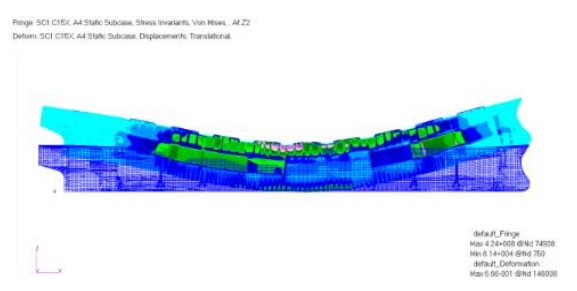

(c)

Figure 5. Ship deformation at $t=0.75$ T. (a) $5 \mathrm{kn}$; (b) $10 \mathrm{kn}$; (c) $15 \mathrm{kn}$.

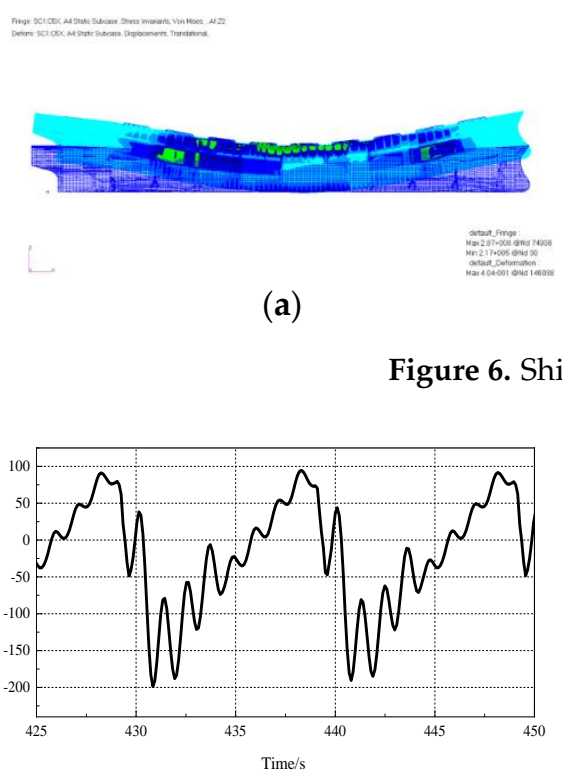

(a)

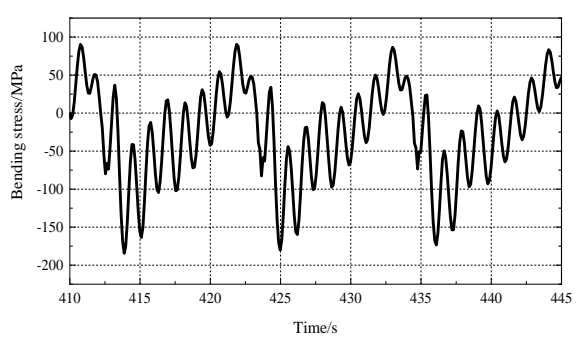

(b)

(b)

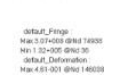

(c)

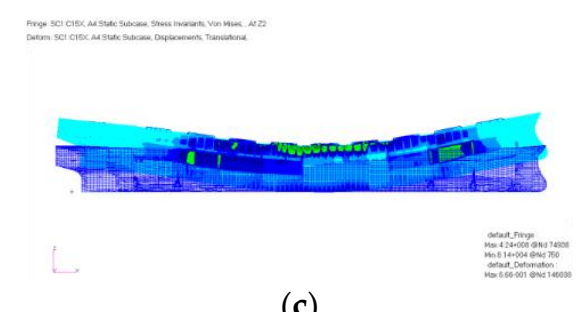

(c) $15 \mathrm{kn}$.

Figure 7. Time histories of deck stresses of the maximum stress section. (a) 5 kn; (b) 10 kn; (c) 15 kn.

\section{Analysis of the Results from Dynamic Method}

\subsection{Influence of Slamming on Bending Moments}

Before the contrast analysis of dynamic response, the wave loads of the dangerous crosssection in time domain need to be predicted based on the nonlinear hydroelastic method, and then the time-domain bending stresses can be obtained by the classical beam theory.

In this paper, the time-domain bending moments were predicted at $5 \mathrm{kn}, 10 \mathrm{kn}$ and $15 \mathrm{kn}$, as shown in Figures 8-10. It is shown that nonlinearity computation may be necessary, especially for hydroelasticity of high-speed vessels. The total amplitudes of bending moments increase with increasing forward speed; there is also a considerable growth in the high-frequency load components. Generally speaking, the high-frequency oscillation includes both springing and whipping components even in high sea states where whipping is dominant, which is a common phenomenon for hydroelastic analysis. As is 
known, whipping corresponds to the modal force produced by the slamming force, so the slamming effect has a main impact on the high-frequency characteristics of load responses. If hydroelastic responses of high-speed ships are studied, the contribution of slamming force to the hydroelastic responses is indeed not negligible. Besides, for the low-speed condition $(U=5 \mathrm{kn})$, there is no great difference between without the slamming effect and with the slamming effect. However, for the high-speed conditions, the high-frequency characteristics are more obvious if the slamming effect is considered.

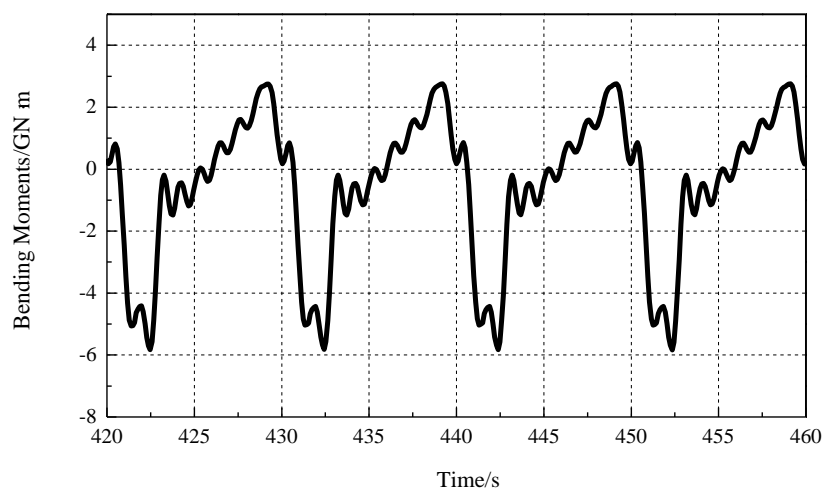

(a)

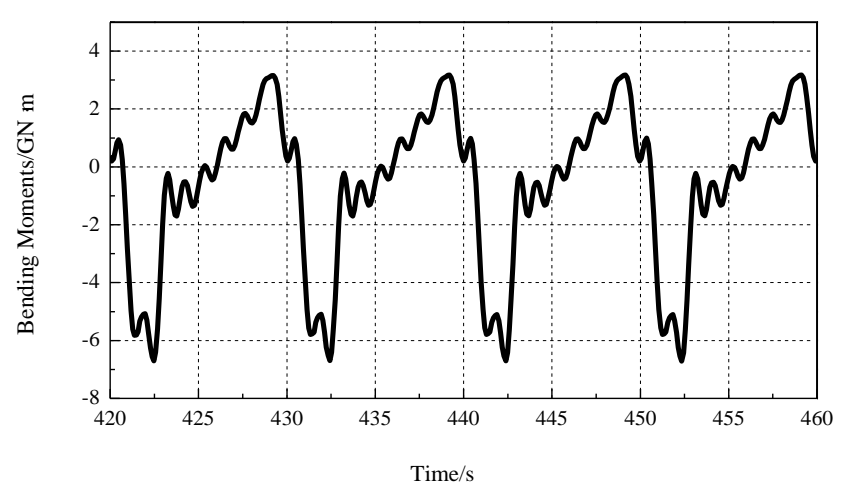

(b)

Figure 8. Time histories of bending moments $(U=5 \mathrm{kn})$. (a) Without slamming effect; (b) With slamming effect.

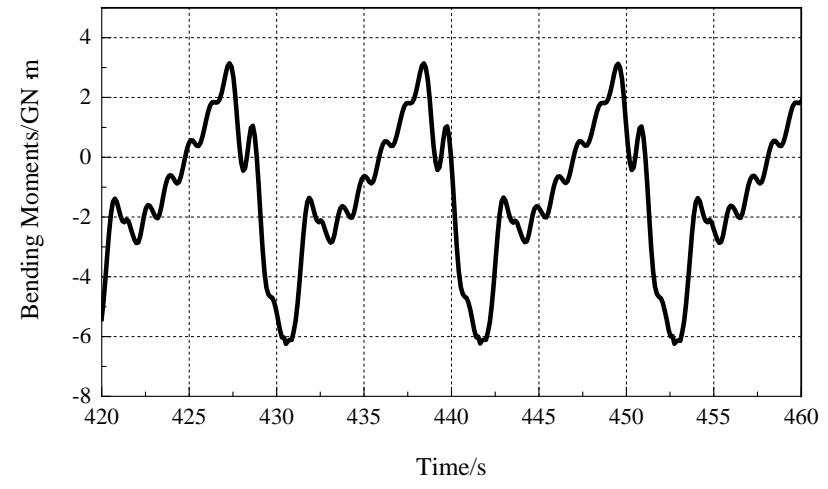

(a)

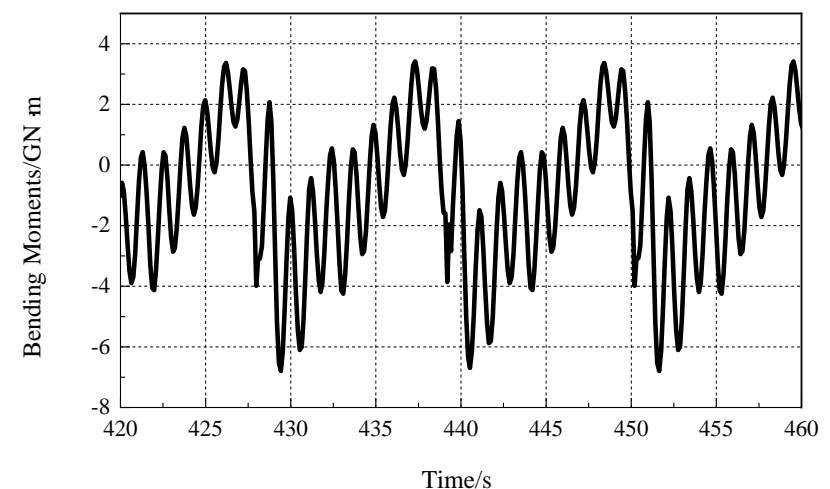

(b)

Figure 9. Time histories of bending moments $(U=10 \mathrm{kn})$. (a) Without slamming effect; (b) With slamming effect.

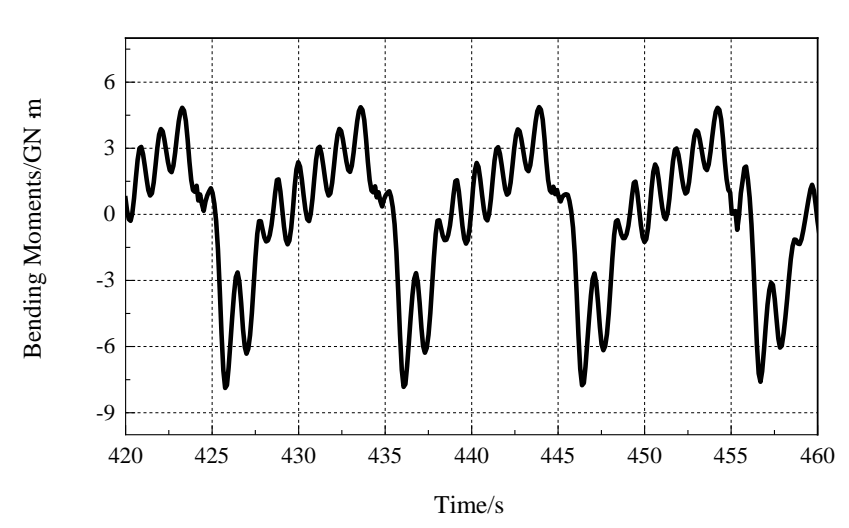

(a)

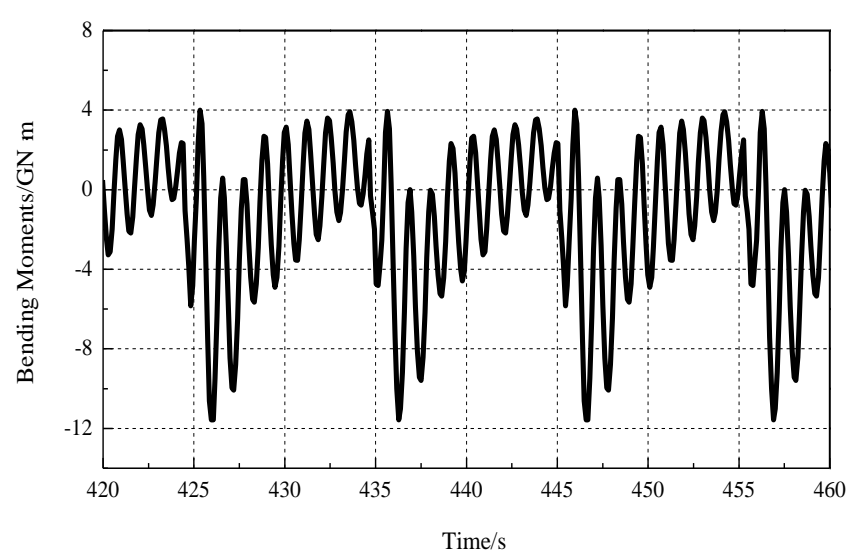

(b)

Figure 10. Time histories of bending moments $(U=15 \mathrm{kn})$. (a) Without slamming effect; (b) With slamming effect. 
Furthermore, Table 4 lists the hogging and sagging values from the time histories of bending moments above. As shown in Table 4, whether or not slamming is considered, the amplitudes of bending moments increase as the forward speed increases. As the forward speed increases, the ratio of bending moments with slamming effects to bending moments without slamming effects increases. This indicates that concerning the growth of forward speed, the slamming effect has a more obvious influence on bending moments, especially for the sagging values.

Table 4. Comparison of bending moments (GNm).

\begin{tabular}{ccccc}
\hline \multicolumn{2}{c}{ Loading Condition } & \multicolumn{2}{c}{$\begin{array}{c}\text { Bending Moments } \\
\text { (without Slamming Effect) }\end{array}$} & $\begin{array}{c}\text { Bending Moments } \\
\text { (with Slamming Effect) }\end{array}$ \\
\hline \multirow{2}{*}{$5 \mathrm{kn}$} & Hogging & 3.147 & 3.12 & Ratio \\
& Sagging & -5.941 & -7.14 & 0.991 \\
\multirow{2}{*}{$10 \mathrm{kn}$} & Hogging & 3.127 & 3.485 & 1.202 \\
& Sagging & -6.269 & -7.196 & 1.114 \\
\multirow{2}{*}{$15 \mathrm{kn}$} & Hogging & 4.309 & 3.994 & 0.927 \\
& Sagging & -8.162 & -11.756 & 1.440 \\
\hline
\end{tabular}

\subsection{Comparison of Dynamic Stress with/without Slamming Effect}

As for the structural responses, the classical beam theory is chosen as the verification. Based on the time histories of bending moments obtained above considering slamming effect, the time histories of bending stresses may be obtained by the method in Section 3.1, and compared with the upper deck bending stresses of the dangerous cross-section by using dynamic analysis method, as shown in the Figure 11. In general, the results from the dynamic analysis method are nearly identical with the bending stresses from the classical beam theory, which shows that the dynamic analysis method for the hull bending stresses is reliable. Moreover, with the increasing of forward speed, the agreement between these two results is getting lower.

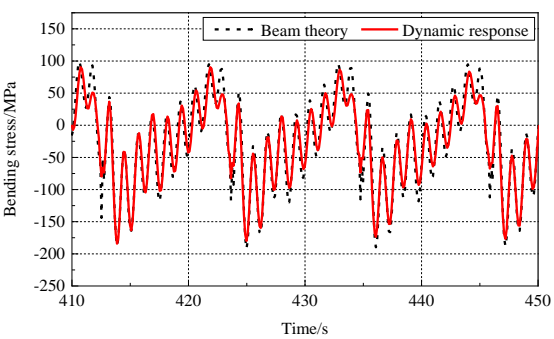

(a)

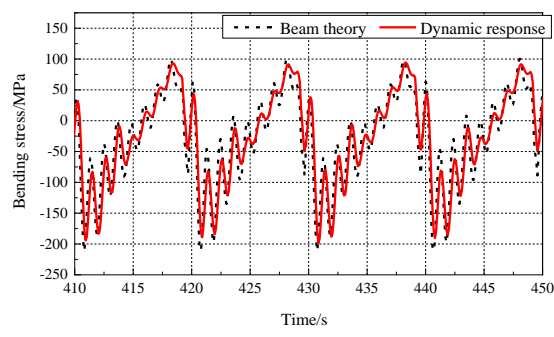

(b)

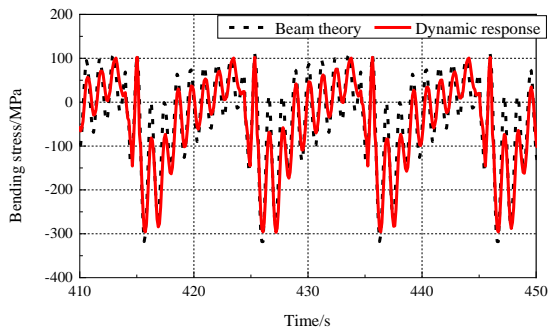

(c)

Figure 11. Time histories of bending stresses. (a) 5 kn; (b) 10 kn; (c) 15 kn.

Since the maximum stress is paid the most attention in the analysis of ship structure strength, the focus of this article is the comparison of peaks. The Table 5 lists the hogging and sagging values of different methods. As shown in Table 5, error 1 denotes the differences between static data and classical beam theoretical data, and error 2 denotes the differences between dynamic data and classical beam theoretical data. Compared with the quasi-static results, the dynamic analysis results are closer to the results from the classical beam theory. Besides, with the increasing of forward speed, the agreement of these two methods with the classical beam theory reduces. The primary reason is that slamming is playing more significant roles in the extreme sea states, and the dynamic analysis may better capture nonlinear characteristics of load responses. 
Table 5. Bending stresses from different methods (with slamming effect).

\begin{tabular}{cccccc}
\hline \multirow{2}{*}{ Loading Condition } & $\begin{array}{c}\text { Quasi-Static } \\
\text { Method/MPa }\end{array}$ & $\begin{array}{c}\text { Dynamic Analysis } \\
\text { Method/MPa }\end{array}$ & $\begin{array}{c}\text { Classical Beam } \\
\text { Theory/MPa }\end{array}$ & Error 1 & Error 2 \\
\hline \multirow{2}{*}{$5 \mathrm{kn}$} & Hogging & 88.31 & 90.30 & 94.05 & $6.10 \%$ \\
\multirow{2}{*}{$10 \mathrm{kn}$} & Sagging & -175.86 & -179.96 & -186.89 & $5.99 \%$ \\
& Hogging & 89.29 & 95.67 & 101.34 & $11.89 \%$ \\
\multirow{2}{*}{$15 \mathrm{kn}$} & Sagging & -187.95 & -201.34 & -212.85 & $11.70 \%$ \\
& Hogging & 90.04 & 102.16 & 109.84 & $18.03 \%$ \\
& Sagging & -261.54 & -295.86 & -317.79 & $6.99 \%$ \\
\hline
\end{tabular}

In addition, for the high forward speed conditions, the errors of quasi-static results exceed the range of safety permissible. Although the errors of dynamic analysis method are larger at high speed than those at low speed, the dynamic analysis method still satisfies the project requirements. Therefore, in case of slamming or high-speed condition, the dynamic analysis method is more suitable to the prediction of the structural responses of hulls.

As for the calculation without slamming effect, the time histories of hogging and sagging values in the typical loading conditions were obtained and are shown in Table 6 . As shown in the table, compared with the quasi-static results, the dynamic analysis results are closer to the ones of classical beam theory. However, both the quasi-static method and dynamic analysis method can satisfy the accuracy requirement. In this case the static method may be adopted to achieve a compromise between computation efficiency and accuracy.

Table 6. Bending stresses from different methods (without slamming effect).

\begin{tabular}{ccccccc}
\hline \multirow{2}{*}{ Loading Condition } & $\begin{array}{c}\text { Quasi-Static } \\
\text { Method/MPa }\end{array}$ & $\begin{array}{c}\text { Dynamic Analysis } \\
\text { Method /MPa }\end{array}$ & $\begin{array}{c}\text { Classical Beam } \\
\text { Theory/MPa }\end{array}$ & Error 1 & Error 2 \\
\hline \multirow{2}{*}{$5 \mathrm{kn}$} & Hogging & 83.02 & 83.68 & 86.54 & $4.07 \%$ & $3.30 \%$ \\
\multirow{3}{*}{$10 \mathrm{kn}$} & Sagging & -164.78 & -165.79 & -171.63 & $3.99 \%$ & $3.40 \%$ \\
& Hogging & 84.74 & 85.15 & 88.74 & $4.51 \%$ & $4.05 \%$ \\
\multirow{2}{*}{$15 \mathrm{kn}$} & Sagging & -177.79 & -178.74 & -186.15 & $4.49 \%$ & $3.98 \%$ \\
& Hogging & 86.47 & 87.01 & 91.00 & $4.98 \%$ & $4.38 \%$ \\
& Sagging & -250.15 & -251.34 & -262.96 & $4.87 \%$ & $4.42 \%$ \\
\hline
\end{tabular}

\subsection{Applicability of Quasi-Static Method and Dynamic Analysis Method}

After the accuracy of the dynamic response method is confirmed by comparison, the purpose of this part is to study the applicability of the quasi-static method and dynamic analysis methods. The results from the quasi-static method and dynamic analysis method are compared with the standard value, and the error percentage of the dynamic analysis method and the quasi-static method with standard value was analyzed and is shown in Figure 12.

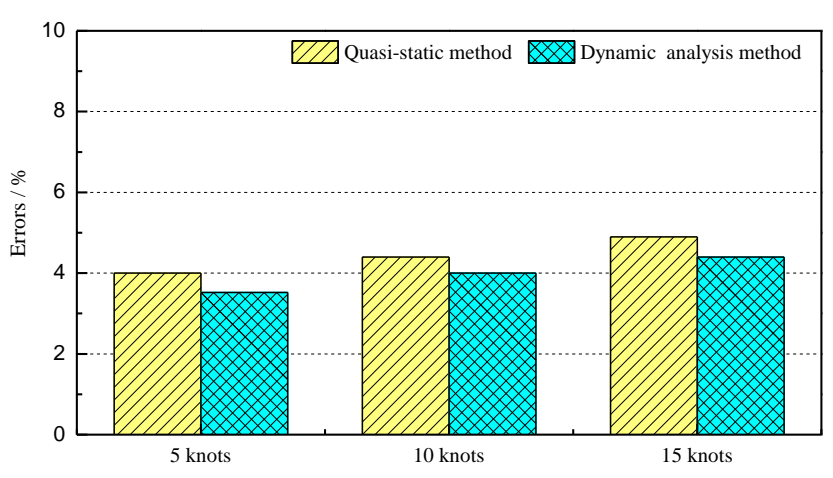

(a)

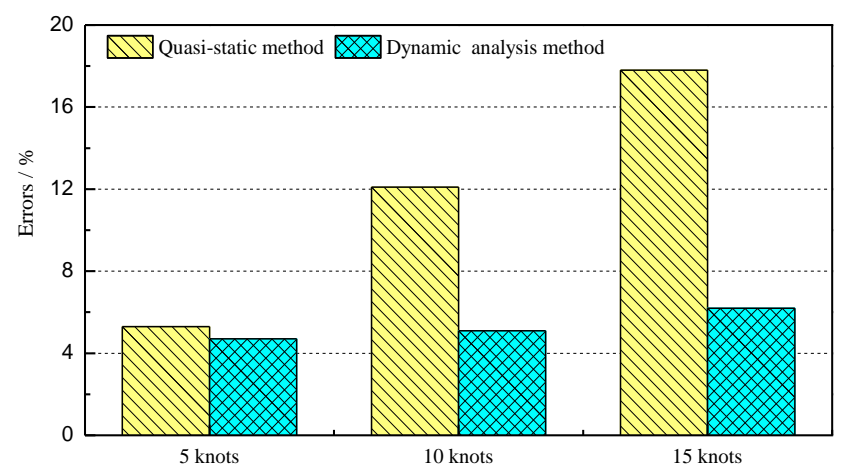

(b)

Figure 12. Errors of the stress. (a) Without slamming effect; (b) With slamming effect. 
As shown in Figure 12a, if the slamming effect is not considered, the dynamic analysis results show a good agreement with the quasi-static results under the three forward speed conditions. The errors of the dynamic analysis method are smaller than those of the quasistatic method. However, in actual engineering, accuracy is not the only reference factor, and the calculation time should also be taken into account. If the slamming effects are not considered, the results of the dynamic analysis method and the quasi-static method are approximately equal, and both of them are reliable. Since the dynamic analysis method is time consuming, the quasi-static method is recommended to be used in this case.

If the slamming effect is considered, it can be observed that there is a big difference between quasi-static results and dynamic analysis results, as shown in Figure 12b. The quasistatic method has low calculating accuracy, and the errors are usually relatively high. Thus, the dynamic analysis method should be used to solve the related problems in this case.

It is worth mentioning that the quasi-static method at low speed can satisfy the project accuracy requirement. As shown in Figure 12a, if bending moments are calculated by the hydroelasticity theory that does not consider the slamming effects, the results from these two methods have little difference. This is primarily because that slamming phenomenon has little effect on load responses at low speed. Hence, the quasi-static method may be used.

\section{Conclusions}

In the present study, the wave loads of a bulk carrier are obtained by 3D nonlinear hydroelastic method. The structural finite element analysis is carried out based on the dynamic response method. The dynamic analysis results are compared with results of the quasi-static method and classical beam theory. The applicability of the dynamic analysis method is discussed and studied. From the present study, the following conclusions can be obtained:

(1) It is feasible to analyze the structural dynamic responses by the nonlinear hydroelastic method. The finite element method based on dynamic response analysis is reliable whether the slamming effect is taken into account or not;

(2) Nonlinear factors may be necessary, especially for structural analysis of high-speed vessels. Different nonlinear factors have different effects on structural responses. The slamming effect has the main impact on the high-frequency characteristics of timedomain structural responses, and the instantaneous wetted surface mainly affects the total stress amplitudes;

(3) If the hydroelastic method considering the influence of slamming is adopted, a great difference between the quasi-static method and dynamic response method will be found. The dynamic method can better capture the nonlinear characteristics and has a higher accuracy;

(4) If it is in the low-speed conditions or the slamming effect is not considered, the dynamic analysis results and the static results are approximately equal, and both of them are reliable. Since the static method can satisfy the accuracy requirement and reduce calculation burden, the static method is recommended to be used in this case.

In the future the authors would develeop an equivalent dynamic coefficient (EDC) based on the above research to achieve accurate and rapid assessment for hull structure strength. The EDC may possess the advantages of both static analysis (high efficiency) and dynamic analysis (high accuracy), which can be applied to transient structural responses of hulls under slamming loads.

Author Contributions: Conceptualization, Z.C. and H.G.; methodology, Z.C.; investigation, Z.C.; software, X.L.; validation, Z.C. and X.L.; formal analysis, M.D.; data curation, M.D.; writing—original draft preparation, M.D.; writing—review and editing, Z.C.; supervision, H.G.; project administration, H.G.; funding acquisition, Z.C. All authors have read and agreed to the published version of the manuscript.

Funding: This research was funded by the Open Fund of State Key Laboratory of Coastal and Offshore Engineering, Dalian University of Technology, grant number LP2001 and The APC was funded by the financial support from the Shandong Provincial Natural Science Foundation, China, grant number ZR2020ME262. 
Data Availability Statement: All data, models, or code generated or used during the study are available from the corresponding author by request.

Conflicts of Interest: The authors declared that they have no conflict of interest to this work.

\section{References}

1. IACS. Common Structural Rules for Bulk Carriers. Int. Assoc. Classif. Soc. 2006, 73-78, 125-141.

2. IACS. Common Structural Rules for Bulk Carriers and Oil Tankers. Int. Assoc. Classif. Soc. 2012, 182-190, 329-380.

3. IACS. Technical Background for Harmonised Common Structural Rules. Int. Assoc. Classif. Soc. 2012, $122-131$.

4. Wei, W.; Fu, S.; Moan, T.; Song, C.; Ren, T. A time-domain method for hydroelasticity of very large floating structures in inhomogeneous sea conditions. Mar. Struct. 2018, 57, 180-192. [CrossRef]

5. Zhang, X.T.; Lu, D.; Gao, Y.; Chen, L.F. A time domain discrete-module-beam-bending-based hydroelasticity method for the transient response of very large floating structures under unsteady external loads. Ocean Eng. 2018, 162, 332-349. [CrossRef]

6. Wu, H.L.; Chen, X.J.; Shen, H.P.; Wu, Y.S. Experimental and numerical investigation of the hydroelasticity of a floating structure with legs. Mar. Struct. 2018, 61, 100-118. [CrossRef]

7. Lavroff, J.; Davis, M.R.; Holloway, D.S.; Thomas, G. Wave slamming loads on wave-piercer catamarans operating at high-speed determined by hydro-elastic segmented model experiments. Mar. Struct. 2013, 33, 120-142. [CrossRef]

8. Lind, S.J.; Xu, R.; Stansby, P.K.; Rogers, B.D. Incompressible smoothed particle hydrodynamics for free-surface flows: A generalised diffusion-based algorithm for stability and validations for impulsive flows and propagating waves. J. Comput. Phys. 2012, 231, 1499-1523. [CrossRef]

9. Lind, S.J.; Stansby, P.K.; Rogers, B.D.; Lloyd, P.M. Numerical predictions of water-air wave slam using incompressible-compressible smoothed particle hydrodynamics. Appl. Ocean. Res. 2015, 49, 57-71. [CrossRef]

10. Xia, Q.Q.; Chen, Z.J.; Li, K.J. Dynamic response of SWATH under slamming loads. J. Vib. Shock. 2011, 30, $208-212$.

11. Lin, Y.; Ma, N.; Gu, X.C. Potential -flow and CFD investigations of bow-flare slamming on a container ship in regular heading waves. Ocean. Eng. 2021, 219, 108278. [CrossRef]

12. Zong, Z.; Sun, Y.F.; Jiang, Y.C.; Sun, T.Z.; Yu, Y.Q. Evolution of slamming load and flow field in water-entry process of trimaran ship section. Ocean. Eng. 2020, 205, 107319. [CrossRef]

13. Sun, Z.; Deng, Y.Z.; Zou, L.; Jiang, Y.C. Investigation of trimaran slamming under different conditions. Appl. Ocean. Res. 2020, 104, 102316. [CrossRef]

14. Wu, J.X.; Sun, Z.; Jiang, Y.C.; Zhang, G.Y.; Sun, T.Z. Experimental and numerical study of slamming problem for a trimaran hull. Ships Offshore Struct. 2019, 16, 46-53. [CrossRef]

15. Li, Q.Y. Structure Strength Assessment of Warship Based on Nonlinear Design Wave Approach; Harbin Engineering University: Harbin, China, 2013.

16. Zhang, N.; Zong, Z. Hydro-elastic-plastic dynamic response of a ship hull girder subjected to an underwater bubble. Mar. Struct. 2012, 29, 177-197. [CrossRef]

17. Aksu, S.; Price, W.G.; Suhrbier, K.R. A Comparative Study of the Dynamic Behavior of Fast Patrol Boat Traveling in Rough Sea. Mar. Struct. 1993, 6, 421-441. [CrossRef]

18. Timman, R.; Newman, J.N. The Coupled Damping Coefficients of a Symmetric Ship. J. Ship Res. 1962, 5, 22-44.

19. Cummins, W. The impulse response function and ship motions. Schisfftechnik 1962, 9, 101-109.

20. Wu, Y.S. Hydroelasticity of Floating Bodies; Brunel University: Brunel, UK, 1984.

21. Chen, Z.Y.; Jiao, J.L.; Li, H. Time-domain numerical and segmented ship model experimental analyses of hydroelastic responses of a large container ship in oblique regular waves. Appl. Ocean Res. 2017, 67, 78-93. [CrossRef]

22. Zhao, Y.P.; Wang, K.K.; Li, Y.-B. Parsimonious regularized extreme learning machine based on orthogonal transformation Neurocomputing 2015, 156, 280-296. [CrossRef] 